\title{
ORIENTAÇÃO EDUCACIONAL NAS ESCOLAS TÉCNICAS ESTADUAIS DE SÃO PAULO: inserção, atribuições e contexto de atuação ${ }^{1}$
}

\section{PAULO ROBERTO PRADO CONSTANTINO}

Centro Estadual de Educação Tecnológica Paula Souza (CEETEPS). Doutor e Mestre em Educação pela UNESP - Marília. Graduado em Música (UEL - Londrina). Professor na Unidade de Pós-Graduação, Extensão e Pesquisa do Centro Estadual de Educação Tecnológica Paula Souza. ORCID: 0000-0002-4612-4063. E-mail: pconst2@gmail.com

\section{MARÍLIA MACORIN DE AZEVEDO}

Centro Estadual de Educação Tecnológica Paula Souza (CEETEPS). Doutora em Engenharia (POLI - Universidade de São Paulo/USP). Mestre em Qualidade pela Universidade de Campinas (UNICAMP). Graduada em Tecnologia de Processamento de Dados (Faculdade de Tecnologia de São Paulo - FATEC SP). Atua na Unidade de Pós-Graduação, Extensão e Pesquisa do CEETEPS. ORCID: 0000-0003-0225-8155.

E-mail: marilia.azevedo@fatec.sp.gov.br

\section{SÉRGIO EUGENIO MENINO}

Centro Estadual de Educação Tecnológica Paula Souza (CEETEPS). Doutorando em Política Científica e Tecnológica no IGE/UNICAMP, Mestre em Tecnologia (CEETEPS). Graduado em

Ciências Econômica (FAAP/SP). Atua na Unidade de Pós-Graduação, Extensão e Pesquisa do CEETEPS. ORCID: 0000-0001-8498-0808. E-mail: sergio.menino@cps.sp.gov.br

1 Os procedimentos éticos requeridos à pesquisa foram observados na coleta e tratamento dos dados, justificando sua procedência de fontes documentais abertas e disponíveis à consulta pública. 


\section{ORIENTAÇÃO EDUCACIONAL NAS ESCOLAS TÉCNICAS ESTADUAIS DE SÃO PAULO:} inserção, atribuições e contexto de atuação

A orientação educacional destinada às escolas de educação profissional está presumida nos documentos oficiais do Estado de São Paulo há quase um século, no entanto, seria disseminada em todo o território paulista somente a partir de 2014. O artigo tem por objetivo delinear a inserção destes profissionais, suas atribuições funcionais e os aspectos destacados de sua atuação, analisando a orientação educacional presente nas Escolas Técnicas Estaduais ligadas ao Centro Estadual de Educação Tecnológica Paula Souza. Baseado em estudos exploratórios, sobre os dados obtidos por meio de pesquisa documental e das experiências de autoria, identificaram-se os primeiros momentos da função, as dificuldades das escolas em obterem candidatos qualificados à função, os eixos de atuação fundamentais destes sujeitos, bem como outras considerações relevantes para uma reflexão sobre a prática e a gestão da educação profissional técnica de nível médio.

Palavras-chave: Orientação Educacional. Educação profissional. Gestão escolar. CEETEPS.

\section{SCHOOL COUNSELING IN VOCATIONAL EDUCATION OF STATE OF SÃO PAULO, BRAZIL:}

\section{insertion, assignments and working context}

The school counseling for vocational education has been presumed in the official documents of the State of São Paulo, Brazil, for almost a century, however, it would only be disseminated as of 2014. The article aims to outline the insertion of these professionals, its functional attributions and the highlighted aspects of its performance, analyzing the school counseling present in the State Technical Schools at the Centro Estadual de Educação Tecnológica Paula Souza. Based on exploratory studies, on the data obtained through documentary research and authorship experiences, the first moments of the function were identified, the difficulties of schools in obtaining qualified candidates, the guidelines of these works, as well as other relevant considerations for a reflection on the practice and management of technical education.

Keywords: School counseling. Vocational education. School management. CEETEPS.

\section{ORIENTACIÓN EDUCATIVA Y PROFESIONAL EN ESCUELAS TÉCNICAS DE SÃO PAULO, BRASIL: admisión, tareas y contexto de trabajo}

La orientación educativa y profesional para las escuelas de educación profesional se presume en los documentos oficiales del Estado de São Paulo, Brasil, durante casi un siglo, sin embargo, solo se difundirá en todo São Paulo a partir de 2014. El artículo tiene como objetivo esbozar la inserción de estos profesionales, sus atribuciones funcionales y los aspectos destacados de su desempeño, analizando la orientación educativa y profesional presente en las Escuelas Técnicas vinculadas al Centro Estadual de Educação Tecnológica Paula Souza. Con base en estudios exploratorios, en los datos obtenidos a través de la investigación documental y las experiencias de autoría, se identificaron los primeros momentos de la función, las dificultades de las escuelas para obtener candidatos calificados, los ejes fundamentales de estas asignaturas, así como otras consideraciones relevantes para una reflexión sobre la práctica y la gestión de la educación técnica.

Palabras Clave: Orientación educativa y profesional. Educación profesional. Gestión escolar. CEETEPS. 


\section{ORIENTAÇÃO EDUCACIONAL NAS ESCOLAS TÉCNICAS ESTADUAIS DE SÃO PAULO: inserção, atribuições e contexto de atuação}

\section{Introdução}

O artigo pretende delinear a orientação educacional nas Escolas Técnicas Estaduais [Etec] de São Paulo, ao explorar aspectos relacionados à trajetória, seleção, qualificação e atribuições funcionais dos atores no âmbito de um sistema público de educação profissional, o Centro Estadual de Educação Tecnológica Paula Souza [CEETEPS ou Centro Paula Souza].

No referido contexto, a função de orientação educacional é fundamentalmente exercida por professores concursados de ensino médio e técnico, aos quais são atribuídas horas de atividades em projetos em cada uma das escolas, com o objetivo de desenvolver ações educacionais coletivas (CEETEPS, 2015).

Enquanto nas escolas estaduais [EE] de educação básica, ligadas à Secretaria da Educação de São Paulo [SEE], existia uma atuação dos orientadores reconhecida em prescrições legais mais antigas (ALMEIDA, 2019a), nas escolas técnicas estaduais [Etec] - ligadas à Secretaria do Desenvolvimento e administradas pelo Centro Paula Souza, esta atuação e a localização do profissional nos documentos oficiais, bem como a extensão de sua oferta a todo o sistema educacional seriam mais recentes, a partir do ano de 2014. Sob esta perspectiva, ao almejar uma compreensão sobre a orientação educacional nas Etecs, torna-se necessário colocar sua adoção e atuação em paralelo com o momento de expansão da instituição, em especial, de seu crescimento exponencial nos últimos vinte e cinco anos.

Uma abordagem do trabalho dos orientadores educacionais na educação profissional seria relevante na medida em que se reconhece, nas últimas duas décadas, um redimensionamento das expectativas sobre este agente, conforme Mirian Grinspun (1994) e Laurinda Almeida (2019a) assinalavam em suas publicações: de uma ênfase na orientação vocacional e nas questões disciplinares, deslocou-se para outros eixos, como a participação efetiva do orientador no projeto pedagógico da escola, questões de execução dos currículos, a constituição das aprendizagens junto aos alunos, o desenvolvimento da ética e da cidadania e a convivência dentro e fora das escolas.

\section{plurais}


O presente texto, portanto, toma parte numa pesquisa mais ampla que vem analisando aspectos educacionais e gestionários das equipes pedagógicas das Etecs - diretores de escolas, coordenadores pedagógicos, orientadores educacionais, auxiliares de docente; dentre outros profissionais, desde o ano de 2012. A metodologia envolveu uma pesquisa documental de caráter exploratório (GIL, 2008) sobre fontes abertas, aliadas à bibliografia disponível, mas também lançou mão das experiências obtidas pelos autores, em mais de uma década atuando diretamente na supervisão escolar, na pesquisa e na formação dos gestores das escolas técnicas estaduais paulistas.

Para organizar este percurso, na seção seguinte foi disposta uma breve fundamentação sobre a orientação, com destaque para o Estado de São Paulo. Num terceiro momento, apresenta-se o mapeamento desta orientação educacional no contexto das Etecs do Centro Paula Souza, ao que se seguem as considerações sobre os achados desta pesquisa.

\section{Breve fundamentação sobre a Orientação Educacional}

O histórico da orientação educacional no Brasil guarda estreita relação com a educação profissional no Estado de São Paulo, com uma presença que remonta a tempos anteriores aos dos demais estados brasileiros.

Conforme relatado por Laurinda Almeida, em trabalhos que resgatam a memória profissional dos orientadores educacionais no âmbito paulista (ALMEIDA, 2014a; 2019b), em 1924 foi fundado um Serviço de Seleção e Orientação Profissional no Liceu de Artes e Ofícios de São Paulo (ALMEIDA, 2019a). Posteriormente, “em 1931, Lourenço Filho, então Diretor do Departamento de Educação de São Paulo, criou o Serviço de Orientação Educacional e Profissional” (ALMEIDA, 2019a, p.114).

Nesta amplificação do atendimento no Estado, Almeida (2019a) assinalava a passagem de uma Orientação Educacional ligada à tradição norte-americana e francesa - de aconselhamento e orientação vocacional e, portanto, com preocupações proeminentes quanto ao trabalho; para uma orientação escolar mais ampla e direcionada à educação básica em geral. No entanto, já no ano de 1932 o serviço seria extinto (ALMEIDA, 2019a).

No âmbito nacional, a Orientação Educacional também foi introduzida na escola brasileira pelo viés da educação profissional, como apreende-se do relato de Almeida (2019a), ao mencionar

\section{plurais}


que os primeiros trabalhos, como os pioneiros no Estado de São Paulo a partir de 1937, "iniciaram-se nas escolas de nível médio que compunham a rede de Ensino Industrial”. (ALMEIDA, 2019, p.115).

Apresentando um panorama histórico do país, a autora mencionava um encadeamento de publicações, que se iniciou pela:

Lei Orgânica do Ensino Industrial, aparecendo depois na Lei Orgânica do Ensino Secundário, a seguir na Lei Orgânica do Ensino Comercial e, posteriormente, na Lei Orgânica do Ensino Agrícola. [Seria] reafirmada pela Lei $n^{\circ} 4.024$ de 20/12/61 e pela Lei $n^{\circ} 5.692$ de 11/08/71. (ALMEIDA, 2019a, p.114)

Uma primeira fase destas atividades de orientação, marcada pelas menções nos textos legais dos anos de 1940 até a obrigatoriedade da presença do orientador educacional na Lei de Diretrizes e Bases [LDB] para o ensino de 1971, foi sintetizada por Almeida (2019a) em seu artigo. Apesar da longa citação, vale restituí-la na íntegra, pela expressão concisa dos cinco principais tópicos que se apresentavam:

$1^{\circ}$ ) Os textos legais consagram desde 1942 a Orientação Educacional como instituição escolar obrigatória; $2^{\circ}$ ) Até a Lei 4.024 de 20/12/68, a maioria dos textos legais refere-se à Orientação Educacional e Profissional; $3^{\circ}$ ) A Lei 5.692 de 11/08/71 usa a expressão Orientação Educacional e introduz Orientação Educacional num sentido amplo, abrangendo tanto Orientação Escolar como Orientação Profissional; e no seu artigo $5^{\circ}$ estabelece: "A parte de formação especial do currículo terá o objetivo de Sondagem de aptidões e iniciação para o trabalho, no ensino de $1^{\circ}$ Grau, e de habilitação profissional no ensino de $2^{\circ}$ Grau". A ênfase da Orientação Educacional recai mais em termos de pesquisa e desenvolvimento vocacional, através do currículo, e menos em termos de ajustamento escolar, o que aparecia nas leis anteriores; $4^{\circ}$ ) Todos os textos legais reconhecem a escolha profissional como objeto da atuação da Orientação Educacional e $5^{\circ}$ ) Os textos legais reconhecem a necessidade de o Orientador cooperar ou articular-se com professores e família. A Lei 5.962/71 é mais explícita, estabelecendo, para o Orientador, uma atuação cooperativa com professores, família e comunidade. (ALMEIDA, 2019a, p.115)

O ano de 1971 foi um marco para os orientadores educacionais, pois a LDB n5692/71 (BRASIL, 1971) trouxe uma concepção alternativa da metodologia de orientação, ao avançar de uma "abordagem mais individual, diagnóstica, de estudo de casos, para uma abordagem mais preventiva, coletiva, que só pode ser conseguida via currículo; portanto, através de um trabalho 
integrado do Orientador" (ALMEIDA, 2019a, p.119). Em um curto lapso de tempo, também ocorreria a regulamentação definitiva da profissão, que se encontrava instituída desde 1968 (BRASIL, 1968), por meio do Decreto 72.846 de 1973 (BRASIL, 1973).

Com a promulgação de uma nova Lei de Diretrizes e Bases da Educação Brasileira, a Lei $n^{\circ}$ 9.394 em 1996 (BRASIL, 1996), reconhecia-se uma vez mais a figura do orientador educacional dentre os profissionais que atuariam na educação básica, citando-lhe nominalmente e reforçando seu prestígio numa redação suplementar de 2009 (BRASIL, 2009):

Art. 61. Consideram-se profissionais da educação escolar básica os que, nela estando em efetivo exercício e tendo sido formados em cursos reconhecidos, são: [Redação dada pela Lei no 12.014 , de 2009]

II - trabalhadores em educação portadores de diploma de pedagogia, com habilitação em administração, planejamento, supervisão, inspeção e orientação educacional, bem como com títulos de mestrado ou doutorado nas mesmas áreas; (Redação dada pela Lei no 12.014 , de 2009)

Art. 64. A formação de profissionais de educação para administração, planejamento, inspeção, supervisão e orientação educacional para a educação básica, será feita em cursos de graduação em pedagogia ou em nível de pósgraduação, a critério da instituição de ensino, garantida, nesta formação, a base comum nacional. (BRASIL, 1996, documento eletrônico)

Entretanto, sob diferentes denominações e em condições diversas, a orientação educacional seria efetivada no Brasil de modo intermitente (GIACAGLIA; PENTEADO, 2011), apesar de prestigiada nos textos legais desde 1942 (ALMEIDA, 2019a; PASCOAL; HONORATO; ALBUQUERQUE, 2008). Segundo Miriam Pascoal (2016), em alguns Estados seria uma figura consolidada, como em "Brasília, Rio de Janeiro, Rio Grande do Sul, Amapá, enquanto em outros, tal profissional não existe" (PASCOAL, 2006, p.115).

Situando uma perspectiva moderna, dentre os pressupostos teóricos de uma abordagem renovada (GRINSPUN, 1994; SANCHES, 1999; PASCOAL, 2006; GIACAGLIA; PENTEADO, 2011; ALMEIDA, 2019a) da Orientação Educacional:

[...] o papel do orientador educacional deve ser o de mediador entre o aluno, as situações de caráter didático-pedagógicas e as situações sócio-culturais. Além disso, a razão de ser da escola e da própria educação é o aluno, centro dos estudos da orientação educacional. (PASCOAL, 2006, p.115)

\section{plurais}


A prática do orientador educacional precisaria ajustar-se às questões pedagógicas e de desenvolvimento das competências socioemocionais entre os alunos, e ao compromisso ético com uma escola democrática, reflexiva e cidadã (SANCHES,1999). Estaria, portanto, para além das questões vocacionais ou profissionais, na importância de promover indiretamente as aprendizagens e, em parceria com outros membros da equipe escolar, "situar o aluno no contexto da escola, tratando questões como indisciplina, desinteresse, agressividade como questões de relações - professor-aluno, professor-conhecimento-aluno, aluno-comunidade" (ALMEIDA, 2019a, p.120).

Ao retomar o olhar sobre o Estado de São Paulo, dois cenários se apresentam no atual momento. As escolas técnicas estaduais [Etecs] paulistas adotariam recentemente a presença do orientador educacional em toda a rede de ensino, a partir de 2014, enquanto nas escolas estaduais [EE] notou-se um evidente retrocesso. Laurinda Almeida ressaltava que, desde 2016, os orientadores educacionais foram extintos da rede pública estadual ligada a SEE (ALMEIDA, 2019a; 2019b) e suas atribuições teriam sido absorvidas por outros atores, como os coordenadores pedagógicos. Para a autora, até o final dos anos de 1980, mesmo com o novo perfil de orientação requisitado,

(...) os orientadores educacionais foram alocados nas escolas sem o suporte necessário do sistema de ensino para seu trabalho. Não se levou em conta o número de alunos das escolas para pensar no módulo para atendimento. Não havia critério para alocação. Tanto uma escola com 200 alunos, como uma escola com 2000 alunos, recebia um orientador. [...] Os diretores, muitos deles, impunham aos orientadores funções que não eram as de seu cargo, tais como supervisionar alunos nos pátios, verificar entrada e saída de alunos e professores, cuidar da disciplina. (ALMEIDA, 2019a, p.119)

Miriam Pascoal atribuía o ocorrido na SEE ao que se referiu como "marcas do passado, em que o orientador educacional exercia uma função de caráter comportamentalista, ligada aos desajustes escolares, o que o confundia com o psicólogo escolar" (PASCOAL, 2006, p.120), o que teria deixado "raízes profundas e difíceis de remover" (PASCOAL, 2006, p.120).

Como se observou na literatura, o orientador educacional é um profissional que precisa ser permanentemente requisitado, debatido e reavaliado nos sistemas educacionais, para que sua atuação não esmoreça. A fim de evitar trajetória assemelhada à da educação básica na educação profissional pública, a seção seguinte procura debater a orientação no contexto das escolas técnicas estaduais de São Paulo, mapeando aspectos relevantes de sua inserção, presença nos textos legais e possibilidades de formação e atuação.

\section{plurais}




\section{A orientação educacional nas Escolas Técnicas Estaduais de São Paulo}

\section{O cenário: a instituição focada e a função da orientação educacional}

Como mencionado anteriormente, para uma compreensão inicial sobre a orientação educacional nas Etecs torna-se necessário colocá-la a par com o momento de expansão da educação profissional pública estadual, no início do século XXI.

No ano de 2020, 223 Etecs eram administradas pelo Centro Estadual de Educação Tecnológica Paula Souza, uma autarquia do Governo vinculada à Secretaria de Desenvolvimento Econômico. Distribuídas por todas as regiões, estas escolas atendiam mais de 224 mil estudantes gratuitamente, somente nos ensinos médio e técnico (CETEC, 2020), além de oferecer qualificação básica, ensino superior em suas 73 Faculdades de Tecnologia [Fatecs] e contar com uma Unidade de Pós-Graduação, Extensão e Pesquisa ${ }^{2}$ (CEETEPS, 2020). Nas duas últimas décadas, entre 2000 e 2019, ocorreu uma forte expansão destas escolas técnicas, passando de 108 para 223 unidades (CETEC, 2020). O crescimento possibilitou o aumento de matrículas em cursos técnicos, demandando também a necessidade de ampliação das funções de apoio e suporte pedagógico (SILVA; CONSTANTINO, 2019), como a referida orientação educacional.

Vale destacar que até o ano de 2012, somente as 34 escolas agrícolas do Centro Paula Souza contavam com um Analista Técnico-Educacional admitido por concurso público - nome funcional recebido pelo orientador educacional desde a década de 2000, com atribuições dispostas na Deliberação CEETEPS n ${ }^{\circ}$ 006/2009 (CEETEPS, 2009) e que serviriam de referência para a constituição do serviço de orientação em toda a rede estadual nos anos seguintes. Sua presença primeiramente nas escolas agrícolas poderia ser explicada pela relação histórica com este tipo de unidade escolar (cf. ALMEIDA, 2019a), além das necessidades observadas na gestão da residência [internato escolar] e na convivência dos alunos em tempo integral nestas Etecs.

\footnotetext{
2 Em 2020, vinham sendo oferecidos 185 cursos técnicos e especializações nas Etecs: 102 cursos técnicos presenciais, 5 cursos técnicos semipresenciais, 5 cursos técnicos online, 3 cursos técnicos na modalidade aberta, 32 cursos técnicos integrados ao Ensino Médio, 28 cursos da modalidade Novotec Integrado, 4 cursos na Articulação da Formação Profissional Média e Superior [AMS) e 6 cursos técnicos integrados ao Ensino Médio na modalidade Educação de Jovens e Adultos [EJA], distribuídos entre todos os eixos tecnológicos do Catálogo Nacional de Cursos Técnicos (BRASIL, 2017). As Fatecs oferecem 80 graduações tecnológicas em diferentes áreas, atendendo mais de 85 mil alunos no ensino superior. A Unidade de Pós-Graduação, Extensão e Pesquisa conta diferentes programas latu e stricto sensu, dentre os quais o curso de Mestrado Profissional em Gestão e Desenvolvimento da Educação Profissional. (CEETEPS, 2020)
}

\section{plupais}

Salvador, v.5, n.1 p.285-304, jan/abr. 2020 
Com a ampliação do número de unidades escolares e a ausência de concursos públicos ou de uma previsão de cargos em número suficiente para todas as Etecs, a função de orientação educacional seria estendida, a partir do ano de 2014, por meio de professores concursados que atuavam no ensino médio e técnico, aos quais seriam atribuídas horas de atividades em projetos, com o objetivo de desenvolver ações educacionais coletivas (CEETEPS, 2015).

Em um primeiro momento desta extensão, a função e as atribuições da orientação educacional se confundiam nos documentos legais com as da coordenação pedagógica, tal como historicamente ocorreu na rede pública paulista ligada à SEE (ALMEIDA, 2019a; 2019b). O Regimento Comum das Escolas Técnicas Estaduais de 2006 (CEETEPS, 2006) atribuía ao Coordenador Pedagógico, então denominado professor responsável pelo Núcleo de Gestão Pedagógica e Acadêmica, entre outras atribuições elencadas no Artigo 25, a de exercer a "orientação educacional e profissional" (CEETEPS, 2006, documento eletrônico), sem mais detalhamentos. A separação destas atribuições ocorreria, nos textos legais, com a publicação de deliberações pelo CEETEPS relacionadas à coordenação pedagógica, em 2012; orientação educacional e um novo Regimento Comum, em 2013. Nesta revisão do Regimento Comum das Etecs (CEETEPS, 2013b), que considerava os planos de carreira do Centro Paula Souza em implantação, as funções seriam finalmente apartadas, com o orientador tomando parte na equipe gestora das unidades, como mencionado no Artigo 26, em seu parágrafo único:

[...] Integra a [equipe de] Coordenação Pedagógica a orientação educacional, destinada a assistir o educando, individualmente ou em grupo, visando ao desenvolvimento integral e harmonioso de sua personalidade, bem como sua orientação profissional. (CEETEPS, 2013b, p.91)

Também no ano de 2013 seria publicada a regulamentação específica da orientação educacional nas Etecs, a saber, a Deliberação CEETEPS nº 02/2013 (CEETEPS, 2013a), que apresentava a função e suas atribuições; e a Instrução Cetec nº5/2013 da Unidade do Ensino Médio e Técnico do CEETEPS, que expedia "instruções complementares a fim de disciplinar as atividades do Professor Coordenador de Projetos Responsável pela Orientação e Apoio Educacional nas Escolas Técnicas" (CEETEPS, 2013c, p.01), relacionada às condições funcionais, de admissão e ao número de horas destacadas a estes profissionais nas escolas.

No Quadro 1, apresenta-se o histórico dos textos legais do CEETEPS ligados à atividade de orientação nas Etecs: 
Quadro 1: Sinopse dos textos legais relacionados ao trabalho de orientação educacional no Centro Paula Souza entre os anos de $2006-2020$

\begin{tabular}{|c|c|c|}
\hline Documento & Ano & Sinopse \\
\hline $\begin{array}{l}\text { Deliberação CEETEPS } \\
\mathrm{n}^{\circ} 02 \text {, de } 30 \text { de janeiro de } \\
\text { 2006. (CEETEPS, 2006) }\end{array}$ & 2006 & $\begin{array}{l}\text { Aprova o Regimento comum das Etecs, e destaca a orien- } \\
\text { tação educacional entre as atribuições do professor respon- } \\
\text { sável pelo Núcleo Pedagógico. }\end{array}$ \\
\hline $\begin{array}{l}\text { Deliberação CEETEPS n }{ }^{\circ} \\
\text { 06, de 05 de fevereiro de } \\
\text { 2009. (CEETEPS, 2009) }\end{array}$ & 2009 & $\begin{array}{l}\text { Regulamenta as atribuições dos empregos públicos, abran- } \\
\text { gidos pelo Plano de Carreira da Lei Complementar nº } \\
\text { 1.044/2008. Entre as atribuições diversas, localizava as do } \\
\text { Analista Técnico-Educacional, que realizaria a orientação } \\
\text { educacional nas escolas técnicas agrícolas. }\end{array}$ \\
\hline $\begin{array}{l}\text { Deliberação CEETEPS } \\
\text { n}^{\circ} 02 \text {, de } 21 \text { de março de } \\
\text { 2013. (CEETEPS, 2013a) }\end{array}$ & 2013 & $\begin{array}{l}\text { Dispõe sobre atividade de Coordenador de Projetos Res- } \\
\text { ponsável pela Orientação e Apoio Educacional nas Escolas } \\
\text { Técnicas Estaduais do CEETEPS. }\end{array}$ \\
\hline $\begin{array}{l}\text { Deliberação CEETEPS } n^{0} \\
\text { 03, de } 18 \text { de julho de } 2013 \text {. } \\
\text { (CEETEPS, 2013b) }\end{array}$ & 2013 & $\begin{array}{l}\text { Aprova o Regimento Comum das Escolas Técnicas Esta- } \\
\text { duais do Centro Estadual de Educação Tecnológica Paula } \\
\text { Souza. Faz menção à figura do orientador educacional em } \\
\text { um de seus artigos. }\end{array}$ \\
\hline $\begin{array}{l}\text { Portaria CEETEPS No } 281 \\
\text { de 3-05-2013 (CEETEPS, } \\
\text { 2013c) }\end{array}$ & 2013 & $\begin{array}{l}\text { Diretora Superintendente do CEETEPS delega competên- } \\
\text { cias ao Coordenador da Unidade do Ensino Médio e Téc- } \\
\text { nico para designar o Professor Coordenador de Projetos } \\
\text { Responsável pela Coordenação Pedagógica e o Professor } \\
\text { Coordenador de Projetos Responsável pela Orientação e } \\
\text { Apoio Educacional das Escolas Técnicas Estaduais. }\end{array}$ \\
\hline $\begin{array}{l}\text { Instrução CETEC n }^{\circ} 05, \text { de } \\
18 \text { de Novembro de } 2013 . \\
\text { (CEETEPS, 2013d) }\end{array}$ & 2013 & $\begin{array}{l}\text { Instruções complementares à Deliberação CEETEPS no } \\
02 \text {, a fim de disciplinar as atividades do Professor Coor- } \\
\text { denador de Projetos Responsável pela Orientação e Apoio } \\
\text { Educacional nas Escolas Técnicas. }\end{array}$ \\
\hline $\begin{array}{l}\text { Deliberação CEETEPS } n^{\circ} \\
18, \text { de } 16 \text { de julho de } 2015 . \\
\text { (CEETEPS, 2015) }\end{array}$ & 2015 & $\begin{array}{l}\text { Dispõe sobre a atividade de Coordenador de Projetos Res- } \\
\text { ponsável pela Orientação e Apoio Educacional nas Escolas } \\
\text { Técnicas Estaduais do CEETEPS. }\end{array}$ \\
\hline $\begin{array}{l}\text { Instrução CETEC n 04, de } \\
28 \text { de junho de 2018. (CEE- } \\
\text { TEPS, 2018) }\end{array}$ & 2018 & $\begin{array}{l}\text { Expede instruções complementares à Deliberação CEE- } \\
\text { TEPS № 018, publicada em } 20 \text { de julho de 2015, a fim de } \\
\text { disciplinar as atividades do Professor Coordenador de Pro- } \\
\text { jetos Responsável pela Orientação e Apoio Educacional } \\
\text { nas Escolas Técnicas. }\end{array}$ \\
\hline
\end{tabular}

Fonte: (CEETEPS, 2006; 2009; 2013a; 2013b; 2013c; 2013d; 2015; 2018)

\section{plurais}


Nos anos de 2015 e 2018, a instituição atualizaria os documentos específicos relacionados à orientação educacional pela última vez, publicando respectivamente a Deliberação CEETEPS $n^{\circ}$ 18/2015 (CEETEPS, 2015) e a Instrução CETEC nº4/2018 (CEETEPS, 2018), em vigência até o presente momento.

Segundo estes textos em vigor, a inserção dos orientadores educacionais nas Etecs decorre de um processo em dois tempos: primeiro, precisam participar de uma qualificação aberta aos professores da rede, que consiste em atender os pré-requisitos ${ }^{3}$ estabelecidos na Deliberação CEETEPS $n^{\circ} 18 / 2015$ e realizar uma prova escrita, que versa sobre a legislação do Centro Paula Souza e as atribuições previstas ao orientador. Após aprovação neste processo de qualificação, o profissional se candidata às vagas disponíveis nas diferentes escolas. Havendo mais de um candidato por vaga, o Diretor da unidade avalia os projetos e opta, sendo que cada unidade admite apenas um orientador.

A admissão para a orientação e apoio educacional só ocorre após parecer sobre o projeto de trabalho por parte da Supervisão Pedagógica Regional e a designação pela Coordenadoria do Ensino Médio e Técnico do Centro Paula Souza. A designação para a função é anual, podendo existir reconduções sucessivas, desde que suas atividades tenham sido aprovadas pela direção e validadas pelo órgão responsável pelas Etecs dentro do Centro Paula Souza.

Sendo indicado, o projeto de orientação e apoio educacional precisa enquadrar-se aos parâmetros de cálculo das horas-atividade específicas [HAE] semanais a serem atribuídas pela Unidade de Ensino Médio e Técnico (CEETEPS, 2018), entre 20 e 40 HAE, variando em função do número de alunos, cursos, professores e turmas ativas na unidade. Além disso, o professor admitido poderá afastar-se de parte ou integralmente de suas aulas, em quantidade equivalente às HAE aprovadas para o seu projeto, desde que haja um professor substituto habilitado na escola. Nestas condições, dependendo da quantidade de horas atribuídas para execução do projeto e da existência de professor substituto para o afastamento, o orientador pode ter que acumular sua função com a de professor, ministrando aulas em uma ou mais Etecs (SILVA; CONSTANTINO, 2019). À remuneração das horas determinadas para realização do projeto, também é disposta uma gratificação de função, representando a metade da gratificação de um diretor de unidade.

3 Entre os requisitos solicitados dos candidatos, estão a necessidade de ser "I - docente contratado por prazo indeterminado [por meio de concurso público, no caso]; II - Estar em exercício no CEETEPS por no mínimo três (03) anos; III - Ser portador de licenciatura; IV - Estar qualificado em processo específico” (CEETEPS, 2015, p. 41).

\section{plurais}


A inserção dos orientadores educacionais nas Etecs: o processo de qualificação

Neste ponto, vale um olhar detido sobre o processo de qualificação para orientadores das Etecs. Sua abrangência deveria ter acompanhado a forte expansão das unidades escolares, porém, entre os anos de 2013 e 2018 foram abertos apenas três processos qualificatórios, dispostos no quadro a seguir:

Quadro 2: Processos de qualificação para professores candidatos à Orientação Educacional nas Etecs

\begin{tabular}{|c|c|c|c|c|}
\hline Ano & Processo & $\begin{array}{c}\mathbf{N}^{\mathbf{0}} \text { de professores qua- } \\
\text { lificados por } \\
\text { processo nas Etecs }\end{array}$ & $\begin{array}{c}\mathbf{N}^{\mathbf{0}} \text { de Etecs exis- } \\
\text { tentes no ano }\end{array}$ & $\begin{array}{c}\text { Média - qualificados por } \\
\text { vaga nas escolas, por } \\
\text { processo }\end{array}$ \\
\hline 2013 & $3587 / 2013$ & 239 & 217 & 1,10 \\
\hline 2015 & $5057 / 2015$ & 545 & 219 & 2,48 \\
\hline 2018 & $771349 / 2018$ & 378 & 222 & 1,70 \\
\hline & & & $\begin{array}{l}\text { Média geral -pro- } \\
\text { fessores qualifica- } \\
\text { dos por escola nos } \\
\text { anos }\end{array}$ & $\mathbf{1 , 7}$ \\
\hline
\end{tabular}

Fonte: (CETEC, 2020)

No ano de 2020, as Etecs do Centro Paula Souza contavam com 10.004 professores na ativa contratados por tempo indeterminado (CETEC, 2020), por meio de concurso público. Todos estes, por princípio, em condições de participar do processo de qualificação à função de orientação educacional. Mesmo sendo possível constatar que as Etecs possuem atendimento, estruturas e tamanhos distintos, o traço comum identificado no Quadro 1 seria a baixa procura pela função, exceto no ano de 2015 , em que 545 professores foram qualificados, proporcionando que uma relação de qualificados por vaga de 2,4 , numa discreta melhoria. É um indicador relevante, mas não definitivo, sobre o processo de seleção nas escolas, já que existiriam unidades que poderiam acusar muitos candidatos e outras que não obteriam nenhum profissional qualificado. Com poucos postulantes às vagas, faltaria oportunidade aos Diretores de Etecs de receberem mais de um projeto, com o intento de avaliar o que mais se adequaria ao perfil de sua unidade e ao projeto político-pedagógico constituído.

Caso não existam professores qualificados à função na unidade escolar ou em consulta às demais Etecs, em casos excepcionais pode ser autorizada a admissão de candidatos não qualifica-

\section{plurrais Savador v.5, n.1 p.2.25-304, jan/abr. 2020}


dos, requisitando apenas que o docente seja um contratado por prazo indeterminado e que possua licenciatura.

Algumas hipóteses poderiam ser consideradas quanto à inserção e a baixa procura pela orientação educacional, de modo semelhante ao observado por (SILVA; CONSTANTINO, 2019) ao examinar outras funções institucionais: 1) que a função de orientação não seria atrativa aos professores por não se tratar de um cargo efetivo e estável, ainda que o argumento do ajuste e flexibilidade aos diretores na escolha dos profissionais possa ser admitido [o que não ocorreria com um orientador concursado em definitivo]; 2) que os candidatos não se sentiriam seguros em candidatar-se ao trabalho em própria sua escola sede, pois mesmo havendo a vaga para a função, pois poderiam ter seu projeto rejeitado pelo Diretor da unidade; 3) que os professores poderiam considerar que as horas de atividade [HAE] atribuídas para execução do projeto não seriam suficientes para se dedicarem ao trabalho de orientação, 4) que pelo fato da orientação educacional não prever uma dedicação escolar exclusiva, em muitos casos o postulante ainda precisaria se manter em sala de aula para completar sua carga horária; 5) que os professores poderiam considerar que a gratificação paga pelo exercício da função não seria suficientemente atrativa; ou 6) que os próprios professores considerem sua formação inicial insuficiente para almejarem à orientação educacional, uma vez que esta formação foi deteriorando-se no país, tendo pouco prestígio nas atuais licenciaturas, cursos de Pedagogia e pós-graduações. Tais hipóteses poderão ser validadas ou revistas em futuras pesquisas.

\section{As atribuições dos orientadores educacionais nas Etecs}

Para uma análise documental das atribuições dos orientadores educacionais na Etecs, abordou-se o conteúdo da Deliberação CEETEPS nº 18/2015 (CEETEPS, 2015). Dispensou-se a análise da Deliberação relacionada aos Analistas Técnico-Educacionais (CEETEPS, 2009) das escolas agrícolas por entender que: 1) $89 \%$ dos orientadores educacionais ativos nas 223 Etecs são admitidos nos moldes da Deliberação CEETEPS nº18/2015; 2) a Deliberação CEETEPS nº18/2015 foi concebida a partir de sua predecessora, encampando parte significativa de seus elementos essenciais.

Extraídos os dados, efetivou-se uma abordagem descritiva baseada na análise de conteúdo (BARDIN,1977), para a compilação dos dados e na construção de categorias de análise das atribuições baseada em grandes eixos de atuação, com a finalidade de agrupá-las no seguinte quadro sinótico:

\section{plurais}


Quadro 3: Atribuições do Professor Coordenador de Projetos responsável pela Orientação e Apoio Educacional nas Etecs e os eixos de atuação identificados

\begin{tabular}{|c|c|}
\hline $\begin{array}{l}\text { Eixos de atuação } \\
\text { identificados }\end{array}$ & $\begin{array}{l}\text { Principais atribuições do Professor Coordenador de Projetos Responsável } \\
\text { pela Orientação e Apoio Educacional nas Escolas Técnicas Estaduais do } \\
\text { CEETEPS }\end{array}$ \\
\hline $\begin{array}{l}\text { Gestão da informa- } \\
\text { ção e assentamentos } \\
\text { escolares }\end{array}$ & $\begin{array}{l}\text { VI - colaborar com a Unidade de Ensino a fim de garantir as informações sobre a } \\
\text { vida escolar dos alunos, encaminhando dúvidas e questionamentos aos órgãos e } \\
\text { servidores competentes; } \\
\text { IX - organizar, junto a Diretoria de Serviços - Área Acadêmica, dados estatísti- } \\
\text { cos referentes à frequência e rendimento dos alunos; }\end{array}$ \\
\hline $\begin{array}{l}\text { Participação em } \\
\text { reuniões e eventos } \\
\text { escolares }\end{array}$ & $\begin{array}{l}\text { I - participar de reuniões pedagógicas, de curso e da equipe gestora, além dos } \\
\text { demais eventos escolares; } \\
\text { VII - reunir-se com pais e responsáveis; }\end{array}$ \\
\hline $\begin{array}{l}\text { Participação no pro- } \\
\text { jeto pedagógico e } \\
\text { plano de gestão }\end{array}$ & $\begin{array}{l}\text { XI - colaborar na elaboração e execução da proposta do Projeto Político Pedagó- } \\
\text { gico e do Plano Plurianual de Gestão; }\end{array}$ \\
\hline $\begin{array}{l}\text { Mediação das rela- } \\
\text { ções interpessoais }\end{array}$ & IV - mediar às relações interpessoais entre os alunos e a escola; \\
\hline $\begin{array}{l}\text { Relações com o } \\
\text { Conselho Tutelar }\end{array}$ & III - acompanhar os casos encaminhados pela direção ao Conselho Tutelar; \\
\hline $\begin{array}{l}\text { Interações com o } \\
\text { corpo docente }\end{array}$ & $\begin{array}{l}\text { VIII - interagir com o Coordenador de Projetos Responsável pela Coordenação } \\
\text { Pedagógica e com o Coordenador de Curso, auxiliando-os na tarefa de fazer com } \\
\text { que o corpo docente compreenda o comportamento dos alunos e das classes; }\end{array}$ \\
\hline $\begin{array}{l}\text { Atuação junto ao } \\
\text { corpo discente }\end{array}$ & $\begin{array}{l}\text { XV - colaborar com demais demandas que contribuam com a formação plena } \\
\text { das competências, habilidades, atitudes e valores discentes dos cursos. } \\
\text { X - buscar a cooperação dos educandos, orientando-os quanto às suas escolhas, } \\
\text { relacionamento com os colegas e professores e vivências familiares; } \\
\text { II - colaborar com a formação permanente do corpo discente, no que diz respeito } \\
\text { aos valores e atitudes, promovendo atividades que levem o aluno a desenvolver a } \\
\text { compreensão dos direitos e deveres da pessoa humana, do cidadão, do Estado, da } \\
\text { família e dos demais grupos que compõem a comunidade, por meio de participa- } \\
\text { ção dos alunos nos órgãos colegiados, tais como Conselhos de Classe e Escola- } \\
\text { res, Grêmio Estudantil, Cooperativas, representação da classe e comissões; } \\
\text { XII - favorecer a articulação entre a vivência do aluno em sua comunidade os } \\
\text { temas abordados em sala de aula, contextualizando a aprendizagem; }\end{array}$ \\
\hline
\end{tabular}




\begin{tabular}{|l|l|}
\hline $\begin{array}{l}\text { Recuperação de } \\
\text { aprendizagem }\end{array}$ & $\begin{array}{l}\text { V - assistir alunos que apresentam dificuldades de ajustamento à escola, proble- } \\
\text { mas de rendimento escolar e/ou outras dificuldades escolares, especialmente na } \\
\text { recuperação e nos casos de progressão parcial, por meio de gerenciamento e co- } \\
\text { ordenação das atividades relacionadas com o processo de ensino-aprendizagem; } \\
\text { XIII - desenvolver nos alunos hábitos de estudo e organização, planejando ativi- } \\
\text { dades educacionais de forma integrada, com a finalidade de melhoria do rendi- } \\
\text { mento escolar; }\end{array}$ \\
\hline $\begin{array}{l}\text { Inclusão de alunos } \\
\text { com deficiência }\end{array}$ & $\begin{array}{l}\text { XIV - planejar e implementar ações referentes à inclusão de alunos com } \\
\text { deficiência, com apoio dos demais departamentos da administração central. }\end{array}$ \\
\hline
\end{tabular}
Fonte: AUTORES, 2020; CEETEPS, 2015, p.41

Entre as 15 atribuições listadas na Deliberação nº18 (CEETEPS, 2015), 9 apresentam uma preocupação expressa com a gestão da aprendizagem dos alunos, baseando-se em aspectos distintos como o ajuste ao projeto pedagógico da escola, o fomento às competências profissionais e gerais, o desenvolvimento de recursos e métodos que favoreçam a aprendizagem. Curiosamente, as atividades relacionadas à orientação vocacional e ao trabalho, tão presentes no início do século XX (cf. ALMEIDA, 2019a), são praticamente abandonadas no documento, sem nenhuma menção específica, exceto pelo item X (CEETEPS, 2015) - que aborda o auxílio e orientação às 'escolhas' feitas pelos estudantes, em um tom genérico. A ênfase da atuação deste professor, portanto, teria sido definitivamente deslocada aos aspectos pedagógicos e de gestão curricular, com vistas à aprendizagem e a permanência estudantil.

Almeida (2019b) afirmava que o orientador educacional não havia sido inserido adequadamente no corpo gestor das escolas estaduais de São Paulo. No caso das Etecs, reconhece-se uma preocupação expressa em diferentes itens do documento, como na participação do orientador no projeto pedagógico e no plano plurianual de gestão das escolas técnicas [cf. item XI], nas interações com o corpo docente [VIII], na participação em reuniões e eventos escolares [I, VII], na gestão e circulação adequada de informações sobre os alunos, colaborando nas decisões da equipe gestora e dos professores [VI, IX]. Tendo visitado e avaliado o trabalho gestionário de muitas escolas nos anos seguintes à inserção dos orientadores educacional, notamos - pela observação não-sistemática do cotidiano das unidades - que o orientador educacional está envolvido na gestão escolar e tem tomado parte na equipe constituída nas Etecs.

Ocorrências isoladas precisam ser constatadas. A inclusão dos alunos com deficiência ganha destaque em um dos itens (XIV), destacando a relevância da temática na instituição, que tem 
realizado um trabalho intensivo para o atendimento educacional especializado, incluindo a adaptação curricular, dos recursos educacionais e a alocação de professores adicionais para atuarem diretamente com os envolvidos.

As relações com o Conselho Tutelar, com o intento de "acompanhar os casos encaminhados pela direção ao Conselho Tutelar” (CEETEPS, 2015, p.41), são parte integrante das atribuições de orientação, atendendo à regulação exigida do aproveitamento escolar dos alunos de menor idade.

As habilidades de comunicação e relacionamento interpessoal se fazem presentes nas expectativas denotadas, não somente para que os orientadores possam "mediar às relações interpessoais entre os alunos e a escola" (CEETEPS, 2015, p.41), mas também interagir com a Coordenação Pedagógica, Coordenador de Curso, o corpo docente e demais atores escolares (CEETEPS, 2015).

Finalmente, entre as sugestões que se apresentam para o aperfeiçoamento da função de orientação educacional nas Etecs a partir desta exploração inicial, estão: a) a promoção de incentivos pecuniários e funcionais [carga horária, condições alternativas de atribuição de aulas e da função] para que o orientador educacional amplie seu envolvimento e exista perenidade no trabalho, sempre que possível; b) consequentemente, a adoção de remuneração em uma faixa salarial com salários e gratificações mais atrativos, baseados em um plano de carreira que se encontra disposto, mas que poderia ser debatido e revisto; c) a carga horária de atuação dos orientadores ser fixada em dedicação exclusiva na unidades escolares, em 40 horas semanais; d) a ampliação dos programas de formação continuada em serviço, de curta duração, voltados especialmente aos orientadores educacionais em campo; e) a criação de programas de pós-graduação lato sensu que atendam as particularidades e auxiliem na resolução de possíveis lacunas na formação deste profissionais em exercício; f) a criação de cursos de formação continuada para os professores que pretendam ingressar na orientação educacional, pois há um desequilíbrio na formação inicial [baixa carga horária nos currículos, pouca oferta nos campi] posto nos cursos de Pedagogia e licenciaturas do país.

\section{Considerações finais}

A existência recente dos orientadores educacionais nas Escolas Técnicas Estaduais de São Paulo foi trazida à ribalta, a fim de compreendê-la e também de provocá-la à luz da literatura e das demandas encontradas no sistema público de educação profissional. Ao expor sua função e

\section{plurais}


contexto de atuação, podemos suscitar não somente o debate acadêmico, mas uma possível reflexão no âmbito escolar e institucional, que por fim poderia amplificar a participação dos professores, seu engajamento e seu interesse na carreira, elevando a qualidade das ações educacionais desenvolvidas e seu alinhamento aos projetos pedagógicos das unidades.

Um aprofundamento sobre o trabalho de orientação nos ensinos médio e técnico ganha relevo ao observarmos o público para o qual se destina: jovens que estão ingressando nas Etecs, oriundos há pouco do ensino fundamental; bem como adultos e idosos que acessam a educação profissional, com expectativas e experiências escolares distintas, mas que exigem igualmente atenção e esforços dos orientadores. Conciliar estas complexas demandas às perspectivas de atendimento em pequenos grupos ou individualizado, atender questões de inclusão e adaptação escolar, tornam o desafio ainda mais elevado.

Sob o ponto de vista institucional, identificou-se que as demandas relacionadas aos orientadores educacionais têm sido: a ampliação da formação continuada destes profissionais, os incentivos para que se dirijam à função e a garantia de alguma perenidade, o que afinal auxiliaria a própria instituição no reforço dos papeis destes profissionais, minimizando a rotatividade nas escolas e ampliando os resultados educacionais esperados.

Não se pretendeu exaurir os múltiplos aspectos relacionados à orientação educacional nas Etecs. Por certo, as trajetórias, modos de seleção e qualificação, a formação e as atribuições funcionais dos orientadores poderão ser objeto de novas investigações em campo, somados às suas expectativas, histórias e memórias profissionais, além dos estudos sobre as políticas públicas, possibilidades de revisão da legislação e da carreira, que se apresentariam como oportunidades para a exploração do campo especificamente ligado à educação profissional.

\section{REFERÊNCIAS}

ALMEIDA, L.R. de. Orientação educacional e coordenação pedagógica no Estado de São Paulo: avanços, recuos, contradições (Parte I). Psicologia da Educação, São Paulo, n. 48, p.113120, jun. 2019a.

. Orientação educacional e coordenação pedagógica no Estado de São Paulo: avanços, recuos, contradições (Parte II). Psicologia da Educação, São Paulo, n. 49, p.117-121, dez. 2019 b. 
BARDIN, L. Análise de conteúdo. Lisboa: Edições 70, 1977.

BRASIL. Presidência da República - Casa Civil. Lei Ordinária no 5.564, de 21 de dezembro de 1968. Provê sobre o exercício da profissão de Orientador Educacional. Diário Oficial da União. 24 dez. 1968. Disponível em: http://www.planalto.gov.br/ccivil 03/leis/1950-1969/ L5564.htm. Acesso em: 30 abr. 2020.

Lei $n^{0}$ 5.692, de 11 de agosto de 1971. Fixa diretrizes e bases para o ensino de $1^{\circ}$ e $2^{\circ}$ graus e dá outras providências. Diário Oficial da União. 28 set. 1971. Disponível em: http:// www.planalto.gov.br/ccivil_03/leis/15692.htm. Acesso em: 30 abr. 2020.

. Decreto n. 72.846, de 26/09/1973. Regulamenta a Lei n. 5.564, de 21 de dezembro de1968, que prove sobre o exercício da profissão de Orientador Educacional. Diário Oficial da União. 27 set.1973.

Lei no 9.394, de 20 de dezembro de 1996. Estabelece as diretrizes e bases da educação nacional. 23 dez. 1996. Disponível em: http://www.planalto.gov.br/ccivil 03/Leis/L9394.htm. Acesso em: 22 abr. 2020.

Lei $\mathbf{n}^{\mathbf{0}}$ 12.014, de 06 de agosto de 2009. Altera o art. 61 da Lei no 9.394, de 20 de dezembro de 1996, com a finalidade de discriminar as categorias de trabalhadores que se devem considerar profissionais da educação. 07 ago. 2009. Disponível em: http://www.planalto.gov.br/ ccivil_03/Ato20072010/2009/Lei/L12014.htm\#art1. Acesso em: 22 abr. 2020.

. MEC. Catálogo Nacional de Cursos Técnicos. 3 ed. Brasília: MEC, 2016. Disponível em: http://portal.mec.gov.br/index.php?option=com docman\&view=download\&alia$\underline{\mathrm{s}}=41271$-cnct-3-edicao-pdf\&category slug=maio-2016-pdf\&Itemid=30192. Acesso em: $30 \mathrm{abr}$. 2020 .

CEETEPS. Deliberação CEETEPS nº 02, de 30 de janeiro de 2006. Aprova o Regimento Comum das Escolas Técnicas Estaduais do Centro Estadual de Educação Tecnológica Paula Souza. Disponível em: http://www.portal.cps.sp.gov.br/quem-somos/departamentos/cgd/legislacao/deliberacoes-2006.pdf. Acesso em: 22 abr. 2020.

Deliberação CEETEPS n ${ }^{\circ}$ 06, de 05 de fevereiro de 2009. Regulamenta as atribuições dos empregos públicos, abrangidos pelo Plano de Carreira, de Empregos Públicos e Sistema Retribuitório, de que trata o artigo 40 da Lei Complementar $n^{\circ} 1.044$, de 13 de maio de 2008, e dá providências correlatas. 06 fev. 2009. Disponível em: http://www.portal.cps.sp.gov.br/quemsomos/departamentos/cgd/legislacao/deliberacoes-2009.pdf. Acesso em: 22 abr. 2020.

\section{plurlais savador v.5, n.1 p.2.285-304, jan/abr 2020}


. Deliberação CEETEPS n 02, de 21 de março de 2013. Dispõe sobre atividade de Coordenador de Projetos Responsável pela Orientação e Apoio Educacional nas Escolas Técnicas Estaduais do CEETEPS. 4 abr. 2013. 2013a. Disponível em: http://www.portal.cps.sp.gov.br/ quem-somos/departamentos/cgd/legislacao/deliberacoes-2013.pdf. Acesso em: 30 abr. 2020.

Deliberação CEETEPS nº 03, de 18 de julho de 2013. Aprova o Regimento Comum das Escolas Técnicas Estaduais do Centro Estadual de Educação Tecnológica Paula Souza. 28 ago. 2013. 2013b. Diário Oficial de São Paulo. Disponível em: http://www.portal.cps.sp.gov.br/ etec/regimento-comum/regimento-comum-2013.pdf. Acesso em: 30 abr. 2020.

Deliberação CEETEPS nº 18, de 16 de julho de 2015. Dispõe sobre a atividade de Coordenador de Projetos Responsável pela Orientação e Apoio Educacional nas Escolas Técnicas Estaduais do CEETEPS. Diário Oficial de São Paulo. 18 jul. 2015. Disponível em: http://www. cpscetec.com.br/cpscetec/doc apoio hae/2019/legislacao vigente.zip. Acesso em: 30 abr. 2020.

. Perfil e histórico do Centro Paula Souza. [Website]. 2020. Disponível em: http://www. cps.sp.gov.br/quem-somos/perfil-historico/. Acesso em: 06 mai. 2020.

Portaria CEETEPS n 281, de 03 de maio de 2013. Diário Oficial de São Paulo. 04 mai. 2013. 2013c. Disponível em: http://www.cpscetec.com.br/cpscetec/doc apoio hae/2019/ legislacao vigente.zip. Acesso em: 30 abr. 2020.

. Unidade do Ensino Médio e Técnico [CETEC]. Instrução CETEC nº 05, de 18 de Novembro de 2013. Expede instruções complementares à Deliberação CEETEPS n no 02 , de 21 de março de 2013 a fim de disciplinar as atividades do Professor Coordenador de Projetos Responsável pela Orientação e Apoio Educacional nas Escolas Técnicas. 2013d.

. Instrução CETEC $n^{\circ}$ 04, de 28 de junho de 2018. Expede instruções complementares à Deliberação CEETEPS n ${ }^{\circ}$ 018, publicada em 20 de julho de 2015, a fim de disciplinar as atividades do Professor Coordenador de Projetos Responsável pela Orientação e Apoio Educacional nas Escolas Técnicas. Disponível em: http://www.cpscetec.com.br/cpscetec/doc apoio hae/2019/legislacao_vigente.zip. Acesso em: 30 abr. 2020.

CETEC. Banco de dados da Unidade do Ensino Médio e Técnico do Centro Paula Souza [CETEC]. [Website]. Disponível em: http://www.cpscetec.com.br/bdcetec. Acesso em: 22 abr. 2020.

GIACAGLIA, L. R. A; PENTEADO, W.M.A. Orientação educacional na prática: princípio, histórico, legislação, técnicas e instrumentos. 6.ed. São Paulo: Cengage Learning, 2011.

GIL, A. C. Métodos e técnicas de pesquisa social. 6.ed. São Paulo: Editora Atlas, 2008. 
GRINSPUN, M.P.S.Z. (Org.) A prática dos Orientadores Educacionais. São Paulo: Cortez, 1994.

PASCOAL, M. O orientador educacional no Brasil: uma discussão crítica. Revista Poiésis, v.3, n. 3-4, p.114-125, 2006.

PASCOAL, M.; HONORATO, E. C. ALBUQUERQUE, F. A. de. Orientador Educacional no Brasil. Educação em Revista, Belo Horizonte, n.47, p 101-120, jun. 2008.

SANCHES, C. Orientação educacional e o adolescente. São Paulo: Arte \& Ciência, 1999.

SILVA, H.C.S; CONSTANTINO, P.R.P. Processo de qualificação para coordenação pedagógica em escolas técnicas estaduais de São Paulo: um estudo exploratório. In: VII Congresso Brasileiro de Educação, Unesp, Bauru, 2019. Anais do VII Congresso [...]. Bauru: Faculdade de Ciências, 2019. Disponível em: https://cbe-unesp.com.br/anais/index.php?t=TC2019081281256\#. Acesso em: 22 abr. 2020.

Recebido em: 30 de abril de 2020.

Avaliado em: 14 de maio de 2020.

Esta obra está licenciada com uma Licença Creative Commons Atribuição 4.0 Internacional. 